\title{
Fruit Packing Feeding Device Based on the ANSYS Analysis Research
}

\author{
Tao Zhang, Jing-shan Zhang, Xin Fan \\ Department of Graduate, Beijing Wuzi University, Beijing, China
}

Email address:

buuzdhzt@126.com (Tao Zhang), zjs19921314@163.com (Jingshan Zhang),310794845@qq.com (Xin Fan)

To cite this article:

Tao Zhang, Jing-shan Zhang, Xin Fan. Fruit Packing Feeding Device Based on the ANSYS Analysis Research. Science Research. Vol. 4, No. 5, 2016, pp. 126-132. doi: 10.11648/j.sr.20160405.14

Received: November 24, 2016; Accepted: November 29, 2016; Published: December 8, 2016

\begin{abstract}
As an agricultural country, China have a large fruit production, the spherical fruits such as apples, oranges were deeply loved by people. At present Chinese fruit export volume is small, mainly because the fruit quality is unable to guarantee the quality of export. The traditional artificial feeding sorting method is of low efficiency and the intensity of labor is heavy. The development of automation at a high speed, automatic feeding and sorting equipment provides a new way of fruit industrialization. Based on the study of spherical fruit's properties and packing properties, take apple as example, analyzing the loading process of packing with the software of ANSYS, this paper design a batch feeding device.
\end{abstract}

Keywords: ANSYS Analysis, Packing, Loading Device

\section{Research Background}

China is a large agricultural country with big fruit production. Apples, oranges and other spherical fruit are popular to the people. But at present, Chinese fruit export volume is very small, mainly due to uneven quality of fruit, can not guarantee the quality of exports. Traditional manual sorting method is of low efficiency [1], heavy labor intensity [2] and accuracy is not high [3]. In the high speed development of the automation, automatic feeding and sorting equipment to provide a new way for fruit industrialization [4]. In this paper, based on the study of the basic properties and packaging properties of spherical fruit (taking apple as an example), this paper designed a batch feeding device.

\section{Typical Properties of Fruit}

In recent years, China's fruit production increased year by year, up to 2014, fruit production reached 262 million 429 thousand and 300 tons [5].

Apple, banana, grape and citrus fruit is the first major fruits in China, but also the most suitable fruit for domestic sales and foreign trade. Apple, whose storage is relatively good and the market demand is large, mainly to fresh sells, is the main fruit of the annual supply market. In the past ten years, the apple planting area has increased year by year, the output has also increased linearly, the number of exports is increasing, but the proportion of total output of exports appears peak, in recent years there is a downward, as figure 1 and figure 2 .

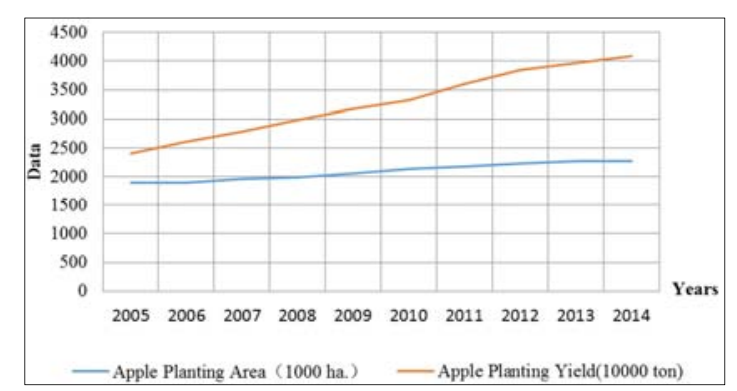

Figure 1. Recent 10 years China's Apple Planting Area and Yield.

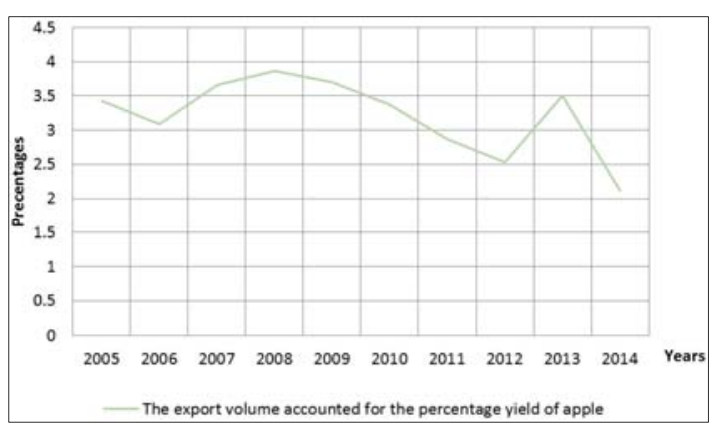

Figure 2. Recent 10 years China's Apple Exports Percentage. 
The kind of apple varieties is more than a dozen. Due to the genetic characteristics there were obvious differences in storage and commodity traits, and the characteristics of the fruit (such as color, flavor, texture, shape, etc.) had a great impact on its sales. The physical and chemical indexes of the main varieties are shown in table 1 :

Table 1. Apple's main varieties of physical and chemical indicators.

\begin{tabular}{|c|c|c|c|c|c|}
\hline Varieties & Hardness of fruit $\left(\mathrm{kg} / \mathrm{cm}^{2}\right)$ & Soluble solid(\%) $\geq$ & Varieties & Hardness of fruit $\left(\mathrm{kg} / \mathrm{cm}^{2}\right)$ & Soluble solid $(\%) \geq$ \\
\hline Fu Shi & 7.0 & 13 & Qin Guan & 7.0 & 13 \\
\hline $\mathrm{Ga} \mathrm{La}$ & 6.5 & 12 & Guo Guang & 7.0 & 13 \\
\hline Ma To 1 & 5.5 & 11 & Hua Guan & 6.5 & 13 \\
\hline Marshal & 6.8 & 11.5 & Red General & 6.5 & 13 \\
\hline Hua Xia & 6.0 & 11.5 & Shan Xia & 6.0 & 12 \\
\hline Pink & 7.5 & 13 & Series of crown & 7.0 & 13 \\
\hline Granny Smith & 7.0 & 12 & Wang Lin & 6.5 & 13 \\
\hline Jonakin & 6.5 & 13 & & & \\
\hline
\end{tabular}

\section{Analysis on the Characteristics of Apple Packaging}

Apple's packaging industry is mature and stable. Packaging box, for inside and outside, the price is from high to low, shape via from small to large, can be made according to the consumer demand. Currently, on the market, apple's packaging box mainly uses corrugated boxes, the size is as following, as table 2:
Table 2. Apple packing case size.

\begin{tabular}{lllll}
\hline & length $(\mathbf{c m})$ & width $(\mathbf{c m})$ & height $(\mathbf{c m})$ & weight $(\mathbf{k g})$ \\
\hline 1 & 41 & 25 & 25 & 8 \\
2 & 50 & 30 & 15 & 9 \\
3 & 40 & 30 & 26 & 10 \\
4 & 42 & 26 & 32 & 12.5 \\
5 & 62 & 41 & 17 & 13 \\
6 & 45 & 28 & 34 & 15 \\
7 & 50 & 30 & 30 & 20 \\
\hline
\end{tabular}

Data source: survey data

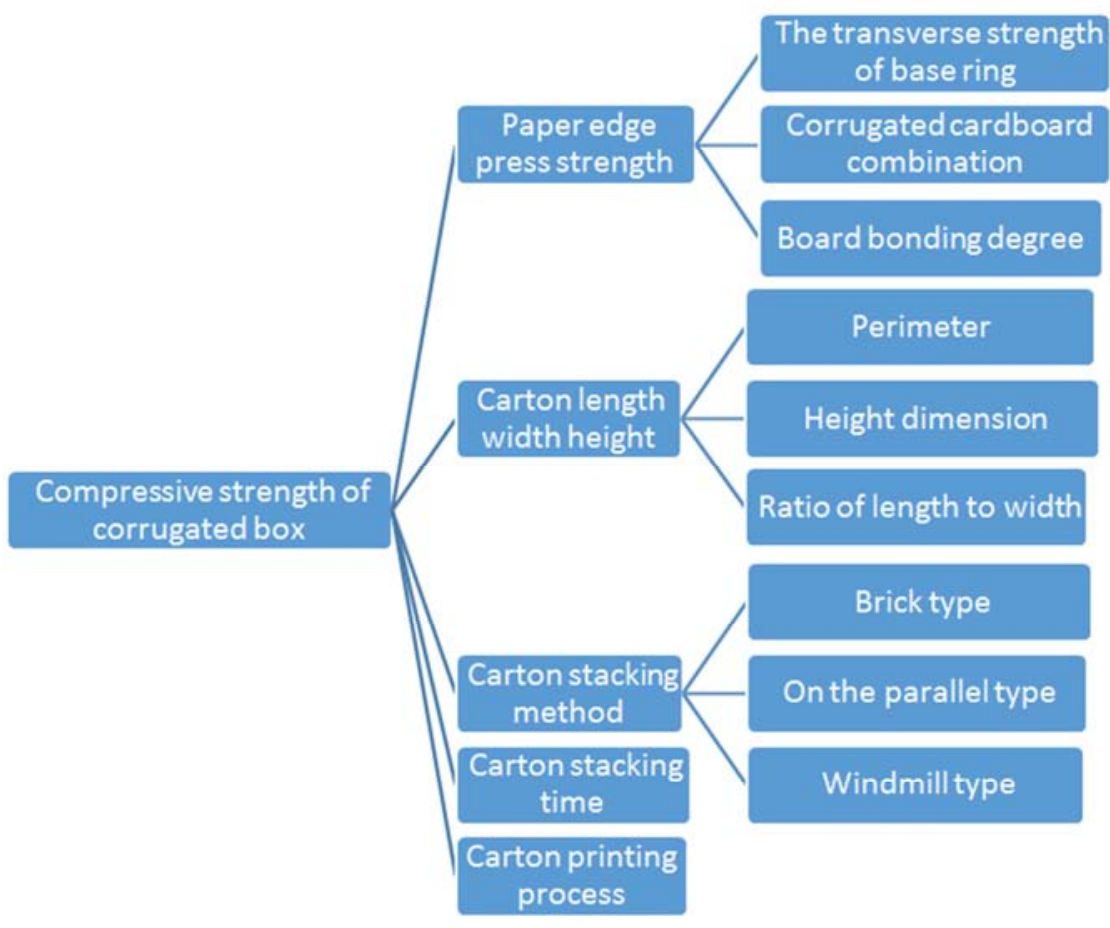

Figure 3. Corrugated box compression strength index.

Introduction of the national standard of corrugated boxes, such as transport with single corrugated boxes and corrugated double standard GB/T 6543-2008, Standard for heavy duty corrugated box for packaging containers GB/T 16717-199, Corrugated box standard GB 6543-1986 The national standards, industry standards and related standards of corrugated paperboard, corrugated box and its materials
GB 5033-85, This paper reference GBT6543-2008 Corrugated paper box in circulation processing. Corrugated cardboard box is mainly to measure the compressive strength, compressive strength and the following indicators:

In the process of circulation, the value of compressive strength of corrugated box is not less than: 


$$
P=K * G(H / h-1) * 9.8
$$

The P value of compressive strength, Newton, unit $(\mathrm{N})$

The safety coefficient of $\mathrm{K}$ - strength, as table 3

Table 3. $K$ - strength safety factor.

\begin{tabular}{llll}
\hline Storage period & $<\mathbf{3 0}$ days & $\mathbf{3 0 - 1 0 0}$ days & $>\mathbf{1 0 0}$ days \\
\hline Deterioration factor $\mathrm{K}$ & 1.6 & 1.65 & 2 \\
\hline
\end{tabular}

Note: the strength safety factor $(\mathrm{K})$ is determined according to the storage period and storage conditions of the cartons.

G- Package quality, Unit kg.

$\mathrm{H}$ - Stacking height (Theoretical height is not more than $300 \mathrm{~cm}$ ).

h- The height of corrugated box.

According to the previous research data, calculate the theoretical value of this type of packaging carton, as table 4:

Table 4. Theoretical Compression Value of Packaging Carton.

\begin{tabular}{|c|c|c|c|c|c|c|c|}
\hline \multirow{3}{*}{ number } & \multirow{3}{*}{ length (cm) } & \multirow{3}{*}{ width (cm) } & \multirow{3}{*}{ height (cm) } & \multirow{3}{*}{ weight (kg) } & \multicolumn{3}{|c|}{ Theoretical compressive strength value } \\
\hline & & & & & $<30$ days & 30-100days & $>100$ days \\
\hline & & & & & 1.6 & 1.65 & 2 \\
\hline 1 & 41 & 25 & 25 & 8 & 1379.84 & 1422.96 & 1724.8 \\
\hline 2 & 50 & 30 & 15 & 9 & 2681.28 & 2765.07 & 3351.6 \\
\hline 3 & 40 & 30 & 26 & 10 & 1568 & 1617 & 1960 \\
\hline 4 & 42 & 26 & 32 & 12.5 & 1568 & 1617 & 1960 \\
\hline 5 & 62 & 41 & 17 & 13 & 3261.44 & 3363.36 & 4076.8 \\
\hline 6 & 45 & 28 & 34 & 15 & 1646.4 & 1697.85 & 2058 \\
\hline 7 & 50 & 30 & 30 & 20 & 2822.4 & 2910.6 & 3528 \\
\hline
\end{tabular}

To sum up, in the case of stacking height within $300 \mathrm{~cm}$, the maximum pressure of the bottom packing cartons' theoretical compressive strength value is $3528 \mathrm{~N}$. Take a $10 \mathrm{~kg}$ packing carton into consideration, the length of storage almost 6 months, the theoretical compressive strength value is $1960 \mathrm{~N}$. We can take every kinds of carton's data to calculate its compressive value.

\section{Force Analysis of ANSYS on Packaging}

Based on the analysis of the properties of the packing box, we designed a kind of feeding equipment, which is suitable for the oblique feeding of bulk materials. Take Num.7 box as the analysis object, built the physical model and ANSYS model to analyze in several key points.

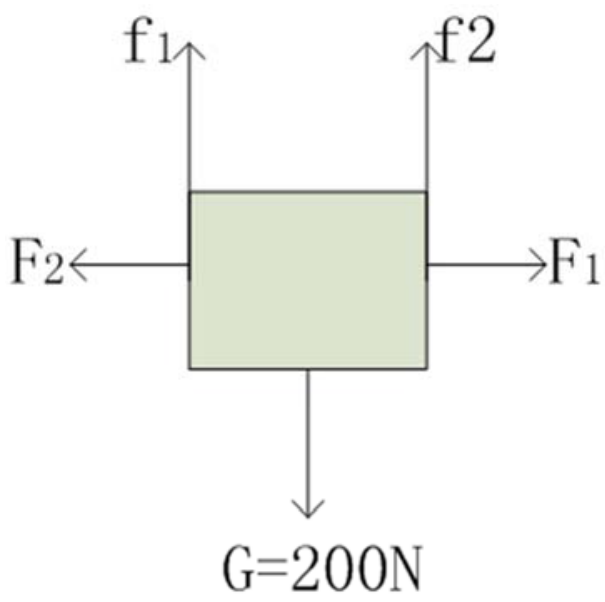

Figure 4. Force analysis.
The friction factor between the clamp and the carton is $\mu=0.2$;

The first situation: Machine holding contact box and the box body just off the ground, this state, bins are in equilibrium, the two sides received equal force F1, F2from holding machine and its vertical direction received gravity and holding friction between machine and cabinet, as figure 4 .

From the equilibrium condition:

$$
\left\{\begin{array}{c}
F_{1}=F_{2} \\
f_{1}=\mu F_{1} \quad F_{1}=F_{2}=500 \mathrm{~N} \\
f_{2}=\mu F_{2} \\
f_{1}+f_{2}=G
\end{array}\right.
$$

In this state, the main stress surface of the box is the two sides and the bottom;

The second situation: Holding machine lifting box, flip the box. The holding machine to the box is still $500 \mathrm{~N}$, the main force is the side of the box, the bottom surface and the front side. The force of bottom and the front face varies with the angle of the flip. Taking apple as the analysis object, with the horizontal direction as the reference surface, the turning box angle is $\theta$, the range of $\theta$ is 0 to 90 , the force from joint force of forth and behind is $F_{3}$, and the force from bottom surface is $\mathrm{F}_{4}$ :

$$
\left\{\begin{array}{c}
\tan \theta=\frac{F_{3}}{F_{4}} \\
F_{3} \sin \theta+F_{4} \cos \theta=G
\end{array}, 0 \leq \theta \leq 90\right.
$$


Make use of MATELAB to make stress change of $\mathrm{F}_{3}$ and $\mathrm{F}_{4}$, as below Figure 5 shown:

\section{Stress Situation}

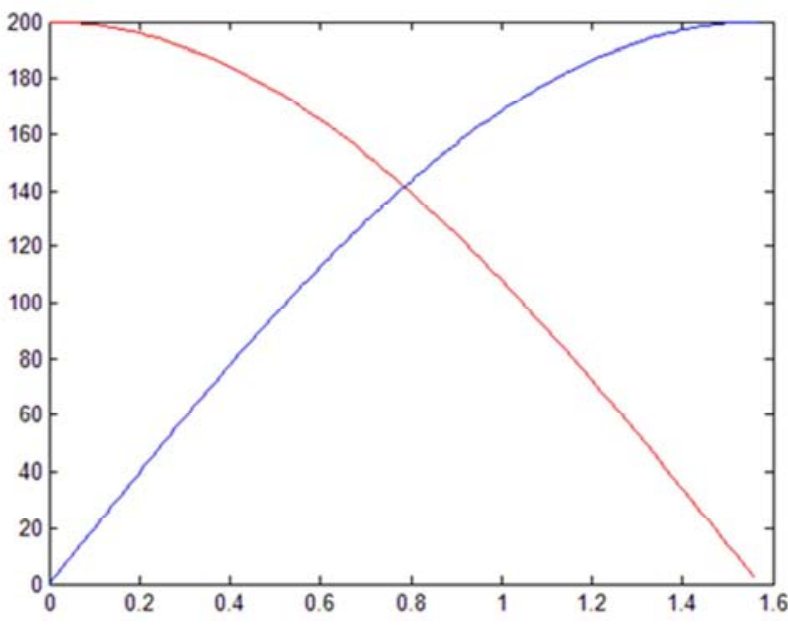

\section{Reversal Angle}

Stress Situation of $F$

Stress Situation of $F_{4}$

Figure 5. Stress analyses of the bottom and front back when the box is turned over.

The third situation: Holding machine turnover box, making apple coming from box. The force of holding machine is still $500 \mathrm{~N}$, but the main force is the back and former sides and the bottom surface, but the force of the back and former sides is follow overturning angle changes;

According to the above process, with the analysis of ANSYS finite element static to get the box structure changes under the corresponding external force, aiming at guide the feeding mode.

For the sake of the finite element calculation, the corrugated box will be simplified under the premise of the result [6]:

1) Ignore the small structure of corrugated cardboard and corrugated cardboard structure, such as a side plate and a top and bottom of the box piece;

2) The corrugated box is equivalent to the growth of the square body, no box top and handle;

3) Due to the experimental conditions, the related parameters of the corrugated box are obtained from the literature;
4) In this paper, we constrained the first four vertices of the box;

Due to the consistency of ANSYS finite element analysis unit, this paper is set to see table 5:

Table 5. Unit sets.

\begin{tabular}{lll}
\hline Classifier & SI & SI(mm) \\
\hline length & $\mathrm{m}$ & $\mathrm{mm}$ \\
load & $\mathrm{N}$ & $\mathrm{N}$ \\
quality & $\mathrm{kg}$ & tonne $\left(10^{3} \mathrm{~kg}\right)$ \\
time & $\mathrm{s}$ & $\mathrm{S}$ \\
stress & $\mathrm{Pa}\left(\mathrm{N} / \mathrm{m}^{2}\right)$ & $\mathrm{MPa}\left(\mathrm{N} / \mathrm{mm}^{2}\right)$ \\
density & $\mathrm{Kg} / \mathrm{m}^{3}$ & tonne $/ \mathrm{mm}^{3}$ \\
\hline
\end{tabular}

ANSYS analysis process and steps see table 6 , its various properties are set to see table $7,8,9$

Table 6. Analysis Process and Steps.

\begin{tabular}{|c|c|c|c|}
\hline Process & steps & Process or result & Remarks \\
\hline \multirow{6}{*}{ Pre-treatment } & & $\mathrm{EX}=2$ & \multirow{4}{*}{ This property is set as table 7} \\
\hline & Define unit properties, & $\mathrm{NUXY}=0.24$ & \\
\hline & material properties & $\mathrm{DENS}=0.55 * 10-15$ & \\
\hline & & $\mathrm{PRXY}=0.24$ & \\
\hline & Building solid model & $\begin{array}{l}\text { First create the coordinates of each vertex, and then } \\
\text { through the key points to create the surface, and then } \\
\text { Boolean operations, connecting the various surfaces, the } \\
\text { geometric model of the corrugated box }\end{array}$ & $\begin{array}{l}\mathrm{X} \text { axis parallel to the length of the carton, } \\
\mathrm{Y} \text { weeks parallel to the carton width direction, } \\
\mathrm{Z} \text { axis parallel to the height of the carton }\end{array}$ \\
\hline & $\begin{array}{l}\text { Finite element network } \\
\text { partitioning }\end{array}$ & Free network partitioning & Partition results as table 8 \\
\hline \multirow[t]{2}{*}{ solve } & Load definition & $\begin{array}{l}\text { The force of the box is converted into the pressure of the } \\
\text { unit area. }\end{array}$ & \multirow[t]{2}{*}{ Results as table 9} \\
\hline & Constraint definition & Constraint box four top vertices & \\
\hline Post treatment & Stress and strain output & & \\
\hline
\end{tabular}


Table 7. Unit Properties and Material Properties.

\begin{tabular}{llll}
\hline & Xiao -li Dai & Yan-ping Fang & Jin-chen Tian \\
\hline density & $5.5^{*} 10^{-4} \mathrm{~kg} / \mathrm{m}^{3}$ & & $5.05 * 10^{6} \mathrm{~Pa}$ \\
Elastic modulus & $5 * 10^{6} \mathrm{~Pa}$ & $3.691 \mathrm{MPa}$ & \\
Poisson ratio & 0.24 & 0.3 & \\
\hline
\end{tabular}

Table 8. Finite Element Network Partition Results.

\begin{tabular}{|c|c|c|c|}
\hline \multicolumn{4}{|c|}{ Solid model summary: } \\
\hline & Largest Number & Number Defined & Number Selected \\
\hline Key points & 23 & 23 & 23 \\
\hline Lines. & 32 & 32 & 32 \\
\hline Areas & 19 & 15 & 15 \\
\hline Volumes. & 2 & 1 & 1 \\
\hline \multicolumn{4}{|c|}{ Finite element model summary: } \\
\hline & Largest Number & Number Defined & Number Selected \\
\hline Nodes & 30432 & 30432 & 30432 \\
\hline Elements. & 15112 & 15112 & 15112 \\
\hline
\end{tabular}

Table 9. Load Constraint.

\begin{tabular}{llll}
\hline AREA & LKEY & LOAD LABEL & VALUE(S) \\
\hline 2 & 1 & PRES & $0.13333 \mathrm{E}-02$ \\
4 & 1 & PRES & $0.55560 \mathrm{E}-02$ \\
10 & 1 & PRES & $0.55560 \mathrm{E}-02$ \\
12 & 1 & PRES & $0.55560 \mathrm{E}-02$ \\
\hline
\end{tabular}

In the process of clamping, the force of the box is shown in the figure below:

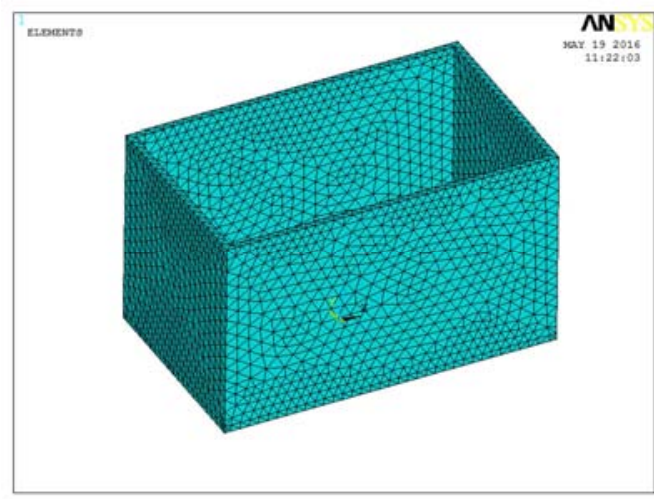

Figure 6. Sketch Map of Network Partition.

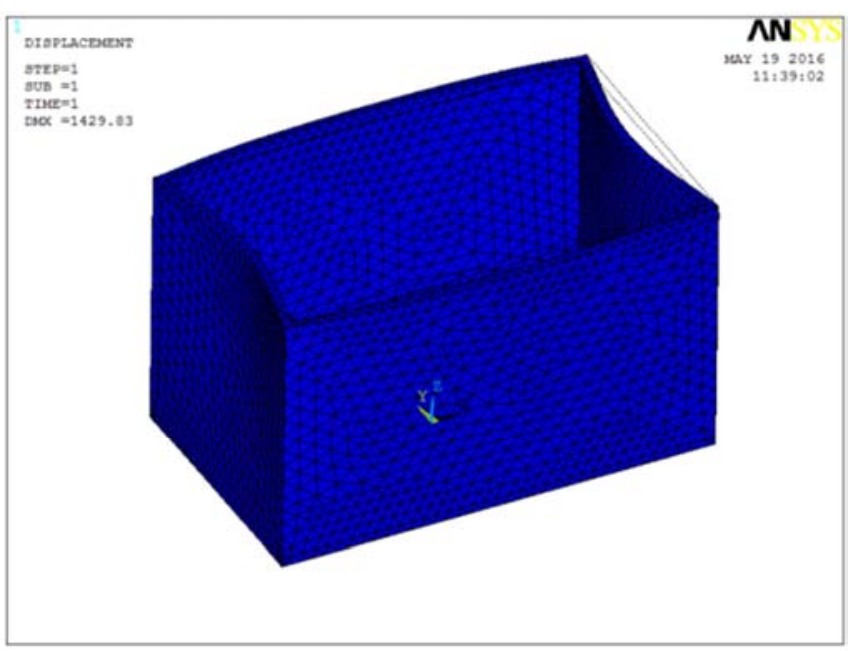

Figure 7. Box Deformation Diagram under I condition.

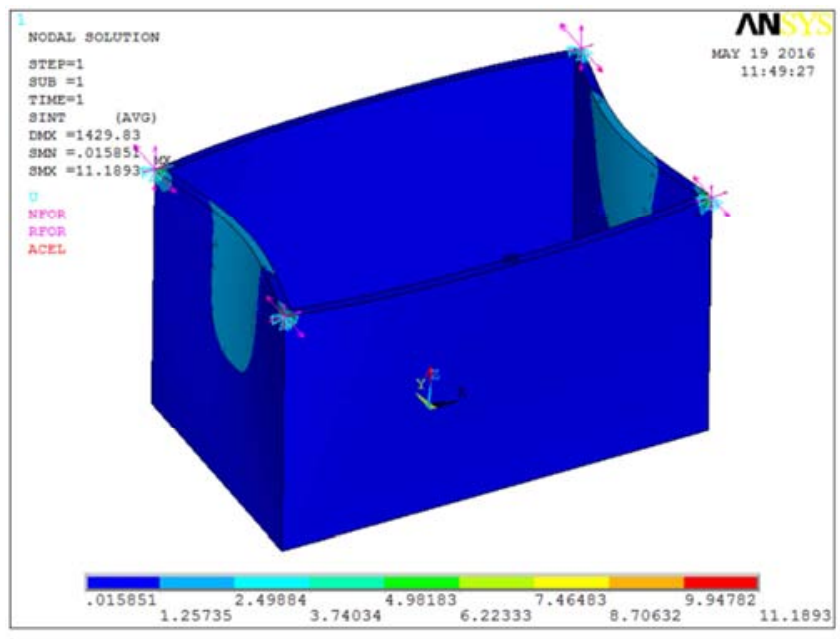

Figure 8. Stress Cloud. 
Below the support plate under the condition of the stress concentration at the bottom of the diagram as follows:

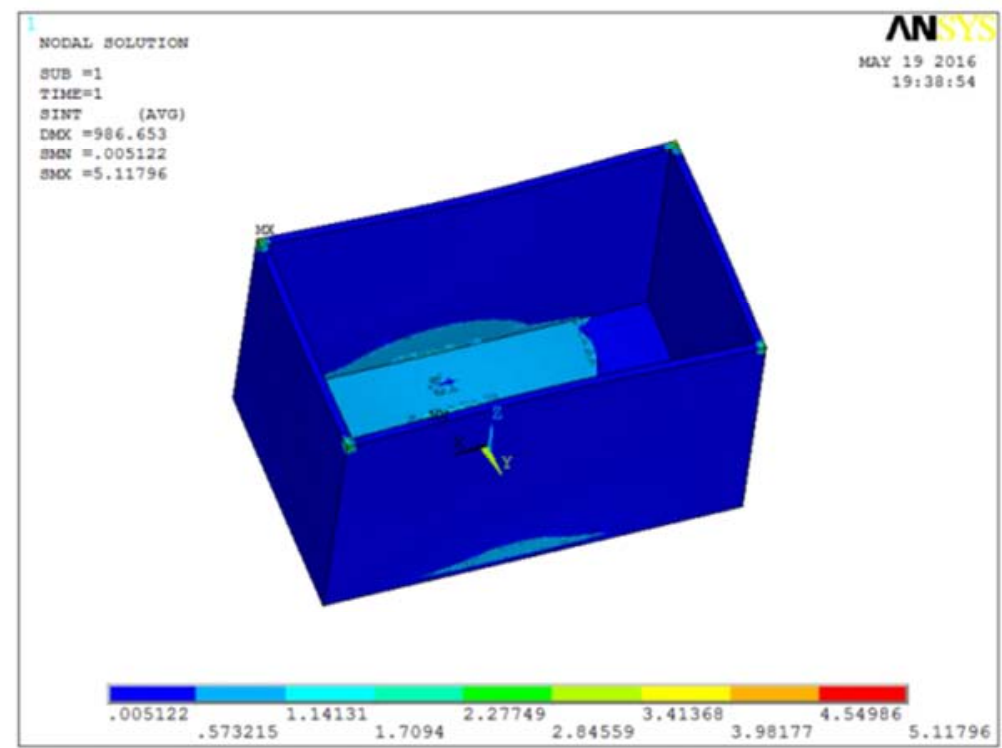

Figure 9. Single point force condition.

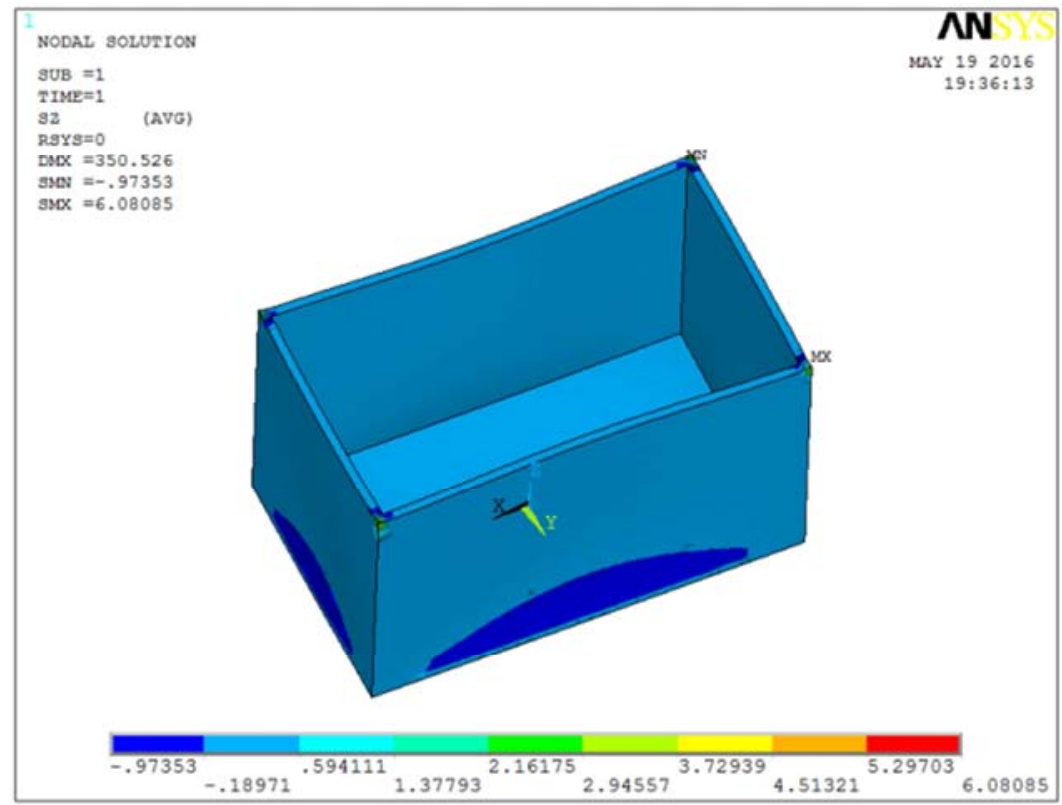

Figure 10. Uniform stress condition.

According to the above analysis, it can be determined that the box can be carried out under the action of the clamping machine, and the force in the range of the allowable compression value can be determined.

Taking above factors into consideration, this paper design of the feeding machine.

\section{Design of Feeding Equipment on Fruit Packing Box}

Though the machine had designed in other country $[7,8,9$, $10]$, they just take main properties and packaging properties into consideration. Based on the analysis of the last section, this paper presents a kind of fruit packing box. The feeding part of the total picture shown as figure 11 is divided into four parts; they are respectively bins holding machine, roller brush, and comb from the physical feeder device and transmission belt from left to right.

The fruit box holding machine: Apple packing box can flip the splint in the role, which will be dumped into the physical device. The front end of the clamping machine is parallel guide rail, so that the clamping machine can clamp the fruit box from one end, and the end of the fruit box can be smoothly transferred to the turning end. One part is the upper end of the 
rotating part, apple will package flip in this part; the other part is the lower part of the lifting part, this part is the role of

holding machine level lifting clamp, Apple will be dumped into the physical material.

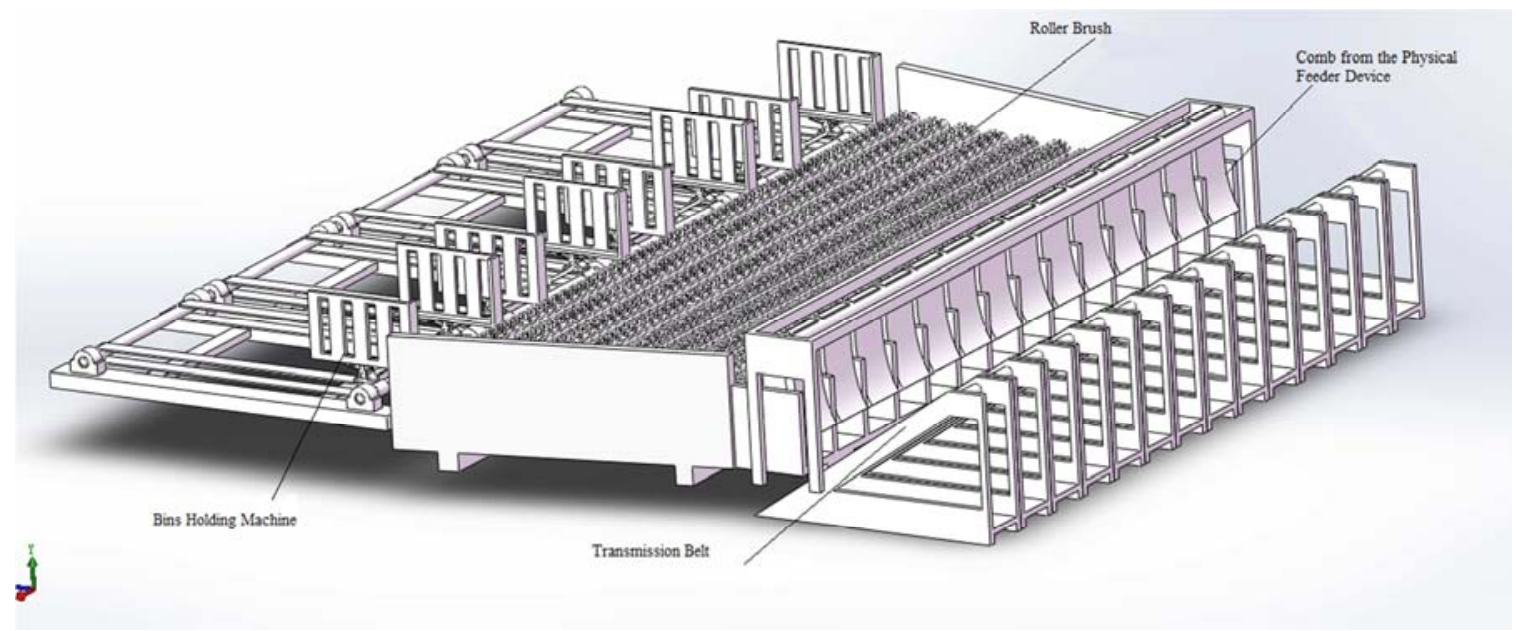

Figure 11. Feeding Device.

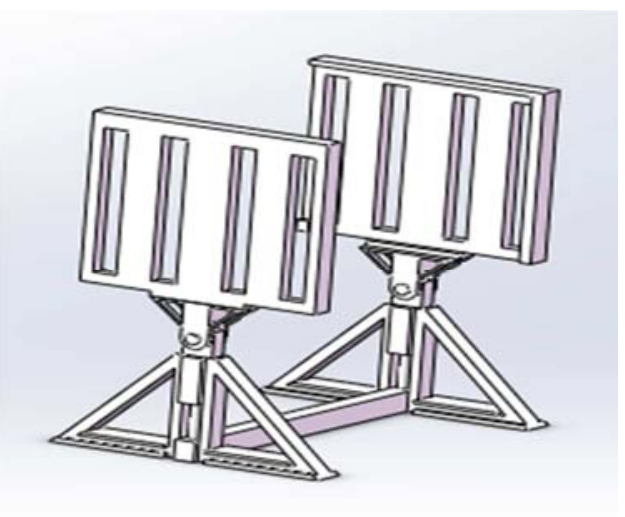

Figure 12. Bins Holding Machine.

The Feeding machine is designed to be wide and narrow in the front and rear, and the combs are separated from the combs into a number of passages to enter the rear conveyor. The width of the front is mainly to ensure the feeding speed. The brush prevents the apple from falling into the transmission process. When the collision, in addition to increasing friction, apple can be successfully transmitted.

\section{Summary}

Based on the main properties and packaging properties of apple, with analysis of ANSYS software of loading process, this paper put forward a device contain holding machine, roller brush and comb from the feeder, and a transmission device, to meet the fruit feeding. Under a ideal protection of flexible material, the device can ensure the quality of products the deep processing of fruit to prevent fruit from mechanical injury.

\section{Acknowledgements}

This paper is based on Beijing Wuzi University Graduate Innovation and Entrepreneurship Project, item number: 0541605843 .

\section{References}

[1] Jian-min Zhu. Automatic recognition method for spherical fruit based on Grey Relational Analysis and fuzzy membership matching [J]. Journal of instrumentation, 2012, 3 (8): 1828-1836.

[2] Ying-long Wang, Hui-hui Xu, Dao-jin Liu, et al. A real-time hierarchical PLC control system for spherical fruit [J]. Journal of agricultural machinery, 2007, 38 (12): 229-231.

[3] Hui-rong Xu, Yi-bin Ying. Research on the double cone roller fruit conveying turnover mechanism [J]. Journal of agricultural machinery, 2003, 34 (6): 100-103.

[4] Ze-nan Wang, a single clear fruit. Mechanical properties and damage of [J]. and food processing machinery, 1986

[5] National Bureau of Statistics of the People's Republic of China. $\mathrm{http} / / /$ www.stats.gov.cn/tjsj/ndsj/.

[6] Meng-hao Cheng, Yun Zhang, Jian-ping Liang. Design and Finite Element Analysis of Tilting and Scale hole Deep Loosening Knife Digging Machines [J]. Journal of Agricultural Mechanization Research, 2016, (7): 137-141.

[7] T. W. ZUV. Viscoelastic Properties of Conveyor Belts Proper Belts. Bulk Solids Handling. December, 2012, Volume 6, Num.3: 1163-1168.

[8] M. Hager, A. Hilte. The Energy-Saving Design of Belts for Long Conveyor Systems. Bulk Solids Handing. Nov, 2011, Volume 13: 749-758.

[9] W. S. W Hubrich. Experience Acquired form Technical Publications. Bulk Solids Handling. Mary2011, Volume 9, Num. 2: 179-187.

[10] Gisbert Schuiz. Comparison of Drives for Long Belt Conveyors. Bulk Solids Handling. Apri1./June 2010, Volume 15, Num.2: 247-251. 